\title{
EVERARDO ADOLPHO BACKHEUSER: UM EXPERT DA EDUCAÇÃO MATEMÁTICA?
}

\author{
EVERARDO ADOLPHO BACKHEUSER: \\ A MATHEMATICS EDUCATION EXPERT?
}

Neuza Bertoni Pinto ${ }^{1, *}$

\begin{abstract}
RESUMO: Analisando o percurso profissional de Everardo Adolpho Backheuser, em suas relações com o contexto educacional das décadas de 1920 e 1930, este estudo indaga sobre a expertise desse educador no campo da matemática escolar, na difusão dos ideais da Escola Nova junto à gestão de Fernando de Azevedo, na Diretoria da Instrução Pública do Rio de Janeiro. A partir de critérios advindos de aportes sócio-históricos, de Hofstetter e Schneuwly; Morais; e Valente, o estudo conclui afirmando o perfil de expert em educação matemática do educador em questão.
\end{abstract}

Palavras-chave: História da educação matemática. Escola Nova. Everardo Adolpho Backheuser. Aritmética da Escola Primária. Expert.

\begin{abstract}
Analyzing the professional career of Everardo Adolpho Backheuser, in his relations with the educational context of the 1920s and 1930s, this study inquires about the expertise of this educator in the field of school mathematics, in the diffusion of the New School ideas under the management of Fernando de Azevedo in the Director of Public Instruction of Rio de Janeiro. Based on criteria derived from socio-historical contributions, by Hofstetter and Schneuwly; Morais; and Valente, the study concludes by affirming that the educator in question has the profile of a mathematics education expert.
\end{abstract}

Keywords: History of mathematics education. New School. Everardo Adolpho Backheuser. Primary school arithmetic. Expert.

\footnotetext{
1.Universidade Federal do Mato Grosso - Programa de Pós-graduação em Educação e Ciências e Matemática Rede Amazônica de Educação em Ciências e Matemática - Cuiabá (MT), Brasil.

*Autora correspondente: neuzabertonip@gmail.com

Número temático organizado por Wagner Rodrigues Valente
} 


\section{Introdução}

Anos 1920, tempo da indústria, tempo de construção de um Brasil moderno e de reformas no cenário da educação brasileira, como a realizada por Fernando de Azevedo entre 1927 e 1930, período em que esteve à frente da Diretoria da Instrução Pública no Rio de Janeiro. ${ }^{1}$

Comparando reformas educacionais realizadas no Rio de Janeiro entre 1920 e 1930, Paulilo (2007) sinaliza para a importância de estudos que busquem compreender mais amiúde os programas das reformas do período em questão. Ao comparar feitos de três reformadores, Carneiro Leão, Fernando de Azevedo e Anísio Teixeira - que, nos anos citados, estiveram à frente da Diretoria da Instrução Pública no Rio de Janeiro -, o autor afirma que os reformadores,

[...] apesar de apresentarem as mesmas inquietações quanto à administração do trabalho educacional, à organização da carreira docente e do sistema público de educação, à implementação das reformas do ensino e ao controle da população escolar. [...] cada qual, a seu modo, esses reformadores elaboraram projetos de reforma, apropriaram-se de soluções alheias, recriaram fazeres ordinários, reinventando cotidianamente o exercício do comando da Diretoria Geral de Instrucção (PAULILO, 2007, p. 384-386).

A Reforma de Fernando de Azevedo, aprovada em 23 de janeiro de 1928 pelo prefeito Antonio Prado Júnior, contou especialmente com a colaboração de inúmeros educadores, entre os quais Everardo Adolpho Backheuser, engenheiro e geógrafo, autor de várias obras voltadas ao ensino primário, como $A$ Aritmética na Escola Nova, que obteve grande repercussão em cursos de formação de professores para os anos iniciais de escolarização. ${ }^{2}$

Indagando sobre a expertise desse último educador no cenário educacional das décadas de 1920 e 1930, o presente estudo se insere no debate atual sobre a constituição de saberes profissionais para ensinar matemática nos anos iniciais de escolarização. Estudos recentes, vinculados a projetos em curso no Ghemat Brasil - Grupo Associado de Estudos e Pesquisas em História da Educação Matemática, ${ }^{3}$ têm viabilizado um olhar sobre a temática. Na busca pela compreensão de tais saberes, historiadores da educação e da educação matemática vêm questionando transformações ocorridas nos saberes profissionais, principalmente em momentos de circulação de novas vagas pedagógicas, nos embates e disputas entre o velho e o novo saber profissional. Nesses estudos são mobilizados conceitos envolvidos na profissão docente, considerados pelos pesquisadores da ERHISE ${ }^{4}$ como os saberes a ensinar e os saberes para ensinar, indispensáveis à compreensão dos processos envolvidos na constituição dos saberes profissionais. ${ }^{5}$ Nos estudos em questão, também é destacada a figura do expert, educador que, em determinado tempo histórico, foi reconhecido por sua contribuição com a institucionalização de saberes legitimados para o ensino e para a formação de docentes. Tais saberes não são fixos, mas elaborados, e decorrem de esforços de educadores, contando com a expertise de um ou vários profissionais experientes, conhecedores tanto da ciência de referência quanto da área do exercício profissional. Neste caso, estamos considerando os educadores da área da educação matemática, espaço em que saberes de diferentes naturezas são colocados em articulação com vistas à produção de um conhecimento novo, que, num determinado tempo, é institucionalizado e reconhecido como matéria prima da profissão docente, tanto no ensino quanto na formação.

Diferentemente de estudos que enfatizam a primazia da experiência docente e dos saberes da ação na docência, as recentes investigações no campo dessa profissão vêm mostrando a premência e o potencial da objetivação e da sistematização como processos indispensáveis para a institucionalização dos saberes da docência e, consequentemente, para a compreensão das transformações que marcaram sua constituição ao 
longo da história.

No campo da educação matemática, Bertini, Morais e Valente (2017), apropriando-se da base teórica advinda da ERHISE, utilizam os termos matemática a ensinar e matemática para ensinar a fim de entender os saberes profissionais considerados essenciais no exercício da docência e, assim, viabilizar novas compreensões sobre o movimento de constituição de tais saberes.

A mútua dependência dos saberes disciplinares - matemática a ensinar - e dos saberes para ensinar - matemática para ensinar - coloca em nível de superação as análises que congelam o saber matemático, cercando-o de didáticas especiais que não têm status epistemológico de saber. Indica-nos que os denominados saberes pedagógicos, didáticos representam uma etapa histórica de promoção do reconhecimento da constituição dos saberes profissionais (BERTINI; MORAIS; VALENTE, 2017, p. 233).

Estudos concluídos no campo da história da educação matemática já vinham analisando transformações ocorridas na matemática escolar nas décadas de 1930 e 1940, como o desenvolvido Pinheiro (2017), mostrando que, em meio a uma vaga escolanovista, destacava-se uma "escola sob medida", a qual visava a um ensino de matemática diferente das décadas anteriores. O estudo de Silva discute transformações ocorridas na estrutura curricular dos Institutos de Educação do Rio de Janeiro e de São Paulo a partir de 1930, com a introdução de disciplinas profissionalizantes e a adoção de saberes especializados na formação de professores, culminado nas décadas de 1950 e 1960, com disciplinas incumbidas de uma aritmética a ensinar e uma aritmética para ensinar (2017, p. 158). Mais recentemente, também foi realizado estudo por Maciel (2019), trazendo significativa contribuição para a análise de processos e dinâmicas de objetivação e sistematização voltados à caracterização de saberes profissionais disponibilizados em manuais pedagógicos de 1880 a 1920, como uma "aritmética para ensinar".

Avançando nas análises das transformações dos saberes, o estudo de D’Esquivel (2019), que centra o olhar nas várias edições do livro Primeiras Noções de Geometria Prática, de grande circulação no Brasil, constatou mudanças ocorridas nos saberes para ensinar geometria no curso primário do final do século XIX à metade do XX. A originalidade do estudo foi reconhecer que Olavo Freire, autor do livro citado, destacou-se como expert ao sistematizar saberes exigidos para o ensino de geometria em diferentes períodos históricos.

Compreender como um profissional do ensino configura um expert não é empreendimento fácil. Requer, entre outras exigências, que o educador não apenas tenha uma expertise, mas tenha, também, realizado uma expertise. Isso significa que esse profissional deve ter contribuído com o processo de sistematização de saberes de campos distintos, articulando-os e elevando-os a novos patamares de profissionalidade; ou seja, à condição de saberes legitimados e institucionalizados (HOFSTETTER; SCHNEUWLY; FREYMOND, 2017).

Recentemente, a REMATEC publicou dossiê ${ }^{6}$ com artigos que descrevem contribuições de educadores, de várias regiões do Brasil, reconhecidos como experts. Segundo Valente (2020a), editor convidado do dossiê, o termo expert é antigo e, ao mesmo tempo, novo, sumariamente significando um indivíduo portador de conhecimentos acumulados em seu ofício. Citando Burke (2016), o editor esclarece que o termo já era usado na Grã-Bretanha desde 1825, quando pessoas especializadas em seus ofícios eram contratadas pelos governos para resolver problemas práticos, em geral relativos a planejamentos, saneamentos e contabilidade. Entretanto, no campo da profissão docente, o termo vem sendo problematizado pela ERHISE e o Ghemat em relação à docência da matemática nos primeiros anos escolares. Expressando novos conhecimentos para a história da formação de professores, os estudos que compõem o dossiê em questão mostram a variedade de experts que, com suas expertises, protagonizaram, em diferentes tempos e espaços geográficos, transformações nos saberes 
para ensinar matemática nos primeiros anos escolares. Trata-se de histórias de educadores matemáticos, em sua maioria desconhecidos e que nem sempre ocupam espaços de notoriedade acadêmica.

Concluindo o editorial do dossiê, Valente ressalta:

A palavra expert está presente no vocabulário da vida cotidiana. E, talvez, por isso, haja sempre muita necessidade de bem caracterizar o termo e sua utilização para o debate sobre a produção de novos saberes. O expert, solitário ou integrante de um grupo, encarna aquele que, tendo recebido a oficialidade da autoridade governamental, a tarefa de viabilizar novas propostas curriculares, elabora novos saberes a estarem presentes como uma matemática a ensinar e uma matemática para ensinar (VALENTE, 2020a, p. 7).

Neste estudo, busca-se problematizar a expertise de Everardo Adolpho Backheuser, que, ao assumir princípios de várias vertentes modernas de ensino da aritmética, optou por um "escolanovismo católico"” para preparar professores para a docência na escola primária.

Organizado em três momentos, o artigo, inicialmente, discute os aportes sócio-históricos que possibilitam analisar conceitos-chave (saberes a ensinar, saberes para ensinar, expert e expertise) que vêm sendo mobilizados em estudos em curso no Ghemat.

A partir da problemática relativa ao conceito de expert, o segundo momento deste artigo foca na trajetória profissional de Backheuser, o que se segue por uma análise dos principais conceitos e ideias disseminados no manual didático Aritmética da Escola Nova, obra que sintetiza o pensamento do autor acerca dos saberes que, em tempos de escolanovismo, são apontados como fundamentais para o ensinar matemática na escola primária, em contraponto com o forte enraizamento herdado de práticas anteriores.

No terceiro momento, reunindo fios dispersos na narrativa com fontes de pesquisa, são discutidos aspectos da trajetória de Backheuser que configuram sua expertise no campo da educação matemática, tendo em vista confirmar ou não seu reconhecimento como expert da educação matemática.

\section{Aportes Sócio-históricos da Expertise}

Vê-se que qualificar um educador como expert requer um olhar mais alargado sobre o atual debate acerca dessa temática, que tem constituído desafio para os pesquisadores. Nesse sentido, é importante compreender a discussão de conceitos dos saberes que interagem na constituição da profissão docente, especialmente naqueles que um expert mobiliza ao realizar sua expertise. Tais saberes, segundo Hofstetter (2017), são alvo de mutações. Trata-se de saberes que passaram por dinâmicas de objetivação e sistematização, processos imprescindíveis na viabilização da institucionalização e da legitimação de conhecimentos apropriados para o exercício da docência.

Com o olhar centrado na profissionalização da docência, Hofstetter afirma que, "nas últimas décadas, a reestruturação da formação de professores realiza-se sem interrupções, mas não sem controvérsias” (2017, p. 17). Nesse sentido, os estudos da ERHISE estão atentos às transformações ocorridas no modo de pensar a formação de professores, notadamente "na compreensão de questões, pressões e contradições dos processos e de seus incidentes concretos na formação e perfis dos professores, mas também daqueles que os formam e dos experts da pesquisa educacional" (HOFSTETTER, 2017, p. 18). Atentos às transformações que ocorrem nos "saberes sobre e para a profissão", saberes para ensinar - saberes profissionais que servem ao ensino e saberes a ensinar - conteúdos escolares e disciplinares (HOFSTETTER, 2017, p. 18) -, os pesquisadores embrenhados nesses contextos têm considerado o papel dos experts nessas pesquisas. Diferentemente de 
possuir uma expertise, habilidade geralmente adquirida com a experiência e inerente a todo profissional, para Schneuwly (2020), são poucos os profissionais “que realizam” uma expertise.

O conceito de expert é antigo e bastante complexo. Atualmente, é muito importante nas pesquisas que investigam processos e dinâmicas da sistematização de novos saberes docentes. Já no fim do século XIX, sendo a escola, ainda profundamente tradicional, adequava-se às expertises realizadas pelos denominados "homens de escola", pessoas da Igreja e filantropos.

No contexto do capitalismo, a introdução de uma escola moderna implica a busca de novas qualificações e um novo modo de realizar uma expertise, a qual passa a ser realizada por meio de uma forte intervenção do estado. É nesse contexto que aparece um novo campo disciplinar acadêmico, "as ciências da educação", o que vai implicar a criação de associações, revistas e congressos - meios que apontem uma nova configuração de expertise. Nesse momento, surgem novas disciplinas e ferramentas científicas são disponibilizadas para o ensino, entre as quais a Psicologia Educacional e a Pedagogia Experimental (HOFSTETTER; SCHNEUWLY; FREYMOND, 2017). Nesse mesmo tempo, no Brasil, há intensa difusão de diversas vertentes da Escola Nova, movimento que faz circular novas e modernas propostas pedagógicas para a escola primária, bem como ações que geram expressivas transformações nos saberes profissionais e, consequentemente, avanços na profissionalização docente - especialmente com as novas ferramentas advindas da Psicologia Experimental, como testes, aumento dos conhecimentos acerca do desenvolvimento infantil e novos mecanismos de aprendizagem. Esses saberes concorrem para a intensa proliferação de manuais pedagógicos, assim como de revistas especializadas, de cunho profissionalizante. Nesse tempo, na formação, as Metodologias Especiais vão tomando o espaço da Didática Geral, passando a inserir em seus programas os manuais especializados numa área de conhecimento.

Um manual pedagógico, ao tratar de um campo disciplinar específico, difundindo e uniformizando discursos de uma nova proposta pedagógica, como afirma Choppin (2000), participa da construção de uma identidade profissional, ao mobilizar saberes a serem ensinados, assim como a melhor forma de ensiná-los. Ao tornar-se mais científica, a formação valoriza a discussão de saberes a ensinar e saberes para ensinar, ${ }^{8}$ conhecimentos que, depois de passarem por processos e dinâmicas de sistematização e objetivação (VALENTE, 2019), são institucionalizados em condições de serem ensinados aos futuros professores. Nessa complexa dinâmica de produção de novos saberes, os experts reinventam sua própria expertise, datando-a historicamente, caracterizando-a.

Como observou Morais (2019), os saberes do ofício docente só adquirem sentido quando historicizados; ou seja, quando o expert, com sua expertise profissional, representa um novo patamar no processo de produção dos saberes de sua temporalidade. Ao eliminar barreiras entre saberes disciplinares (no caso a matemática) e saberes das ciências da educação, o expert da educação matemática dá visibilidade a novos saberes, demostrando, com sua expertise, ${ }^{9}$ ter imprimido, em seu campo profissional, uma identidade distinta dos campos de outras profissões.

Tratando-se de iniciativas presentes em percursos profissionais de educadores brasileiros relevantes para o campo da educação matemática, estudos recentes têm discutido características que permitem atestar a veracidade do conceito de expert, entre as quais estão a produção de novos saberes para ensinar matemática em comparação com propostas anteriores e, principalmente, a chamada (convite ou mandato), por parte do Estado, para que o educador realize uma expertise, objetivando resolver um problema prático para a melhor atuação dos professores.

Nessa perspectiva, tais estudos têm problematizado processos e dinâmicas levados a efeito na trajetória de educadores que propuseram novos saberes para ensinar matemática nos anos iniciais de escolarização. Observa-se, nessa nova vaga, uma valorização não apenas de um saber teórico, mas também de um "saber-fazer" e, ainda, de uma proposta do "saber agir" (MORAIS, 2020). 
Para Morais (2020), atestar que um educador é um expert requer situar sua participação ativa na formação de professores ou no ensino, como produtor de saberes. Para tanto, inspecionam-se, em sua trajetória profissional, os cargos que ocupou e sua participação em funções designadas para a busca de soluções para um problema detectado, bem como descrevem-se os novos saberes produzidos no processo de solução do problema. Além de tais requisitos, a averiguação da documentação encontrada requere uma análise minuciosa e teoricamente fundamentada dos processos de objetivação e sistematização realizados e que resultaram na institucionalização de novos saberes a e para ensinar, no caso, matemática. Sendo um discurso, a expertise realizada pelo expert, para ser reconhecida como tal, necessita ganhar oficialidade. Tal expertise configura um saber cuja natureza envolve a passagem do "cru" para o "cozido" - como diz Burke (2016) ao abordar a transformação da informação em conhecimento. Isso porque ela reúne elementos dispersos a fim de produzir um conhecimento novo; ou seja, um saber resultante de campos disciplinares distintos, que entram em articulação para cumprirem uma nova finalidade. Para tanto, são necessários elementos pertinentes a uma ação específica: a realização de uma expertise que resultará num saber novo, com possibilidade de movimentar e transformar a cultura escolar. Segundo Valente (2020b), trata-se de um saber distinto, que adquiriu novas características depois de passar por um processo de decantação ao longo do tempo (VALENTE, 2020b). Nesse sentido, tal saber está sujeito às relações conflituosas, como bem apontou Julia (2001) ao referir-se às relações que a cultura escolar mantém com outras culturas, quais sejam, religiosas, políticas e econômicas.

Assim, a forma final dos saberes envolvidos, que é atravessada por tensões decorrentes de relações de poder, é sempre advinda de uma instância de poder. Portanto, o reconhecimento e a legitimação de uma expertise profissional não são campos neutros. Valente (2020b) observa que, quando convocado, o expert passa pela tensão da academia e do campo profissional, pois, certamente, os saberes que produz não conseguirão agradar a todos no seu processo de oficialização.

Ao escreverem manuais pedagógicos, os autores poderiam ser reconhecidos como experts? Sim, caso preencham os demais critérios; ou seja, realizem uma expertise a convite de um governo e produzam novos saberes. Contudo, Schneuwly (2020) adverte que essa é uma questão muito complexa, considerando a morosidade das mudanças em educação e a diferença entre a temporalidade da produção de saberes divulgados nos manuais e a temporalidade dos manuais. Nesse sentido, é importante destacar que é a análise do pesquisador, ao relacionar a expertise em seu tempo histórico, que irá aferir se um educador foi um expert.

É a partir dessas problemáticas que este artigo se propõe a discutir a expertise de Everardo Adolpho Backheuser, indagando se o autor da obra A Aritmética na Escola Nova, manual pedagógico que obteve grande circulação em cursos de formação de professores, ${ }^{10}$ pode ser qualificado ou não como expert da educação matemática.

\section{A Trajetória de Everardo Adolpho Backheuser}

Engenheiro, geógrafo, geólogo, jornalista, pedagogo e bacharel em Ciências e Matemática, Backheuser é mencionado por Santos (1989) como possuidor de uma pujante cultura. Nascido em Niterói em 1879, o educador faleceu em 1951, aos 72 anos. Exerceu o magistério como professor catedrático de Geografia no Colégio Pedro II, em 1927; em 1933, no Instituto Católico; e, de 1941 a 1948, na Faculdade de Filosofia Santa Úrsula. Foi também professor de Geopolítica na Escola Politécnica do Rio de Janeiro. 
Estudos sobre esse educador contribuíram para ampliar a descrição de sua trajetória, tratando de diferentes aspectos de sua vida social e de seu percurso profissional e geralmente ressaltando detalhes de suas inúmeras obras dedicadas à educação.

A tese de Rosa (2017), ${ }^{11}$ cujo objetivo foi situar Backheuser no campo educacional brasileiro e compreender como se apropriou dos princípios escolanovistas e os retratou em seus manuais, ressalta que o educador em questão era um "católico escolanovista". Nessa pesquisa, tomam-se como documentos seminais os manuais Técnica da Pedagogia Moderna (Teoria e Prática da Escola Nova), cuja primeira edição é de 1934, e Manual de Pedagogia Moderna (Teoria e Prática), cuja primeira edição é de 1942, que são tratados como manuais norteadores do "escolanovismo católico", "uma espécie de terceira via entre o velho representado pela dita escola tradicional e o novo representado pela modernidade trazida pela Escola Nova” (ROSA, 2017, p. 99). Segundo a tese, Backheuser,

[...] logo que se aposentou como professor, ficou interessado na reforma que Fernando de Azevedo iniciara no Rio de Janeiro em 1927, e passou a colaborar com o mesmo. Na Alemanha, conheceu de forma mais profunda o ideário da Escola Nova e, logo que voltou, assumiu a direção de cinco escolas municipais do Distrito Federal para experimentar alguns métodos e analisar resultados (ROSA, 2017, p. 35).

O "escolanovismo católico backheusiano"12 foi um "projeto educacional que, ancorado na Encíclica Papal Divini Illius Magistri, depurou a Escola Nova daquilo que contrariasse os preceitos católicos e que buscou aliar a razão e espiritualidade, ciência e religião" (ROSA, 2017, p. 221). Defendia-se uma pedagogia científica que fizesse melhor uso da psicologia e da biologia, colocando a Gestalt e a Biotipologia a serviço de uma proposta de educação integral que considerasse a iniciativa, a cooperação e o preparo para a vida pela vida.

Também era defendido o uso de testes, porém, diferentemente de Lourenço Filho, esses não eram concebidos apenas para ajustar comportamentos do aprendiz. Seriam utilizados, também, para o "mestre chegar à essência do aluno e nela agir" (ROSA, 2017, p. 223). Nesse aspecto, nota-se uma dimensão ideológica do educador a favor de um currículo voltado para a vida presente e para o plano sagrado.

O estudo de Gonçalves, A Cruzada Pedagógica pela Escola Nova e ação do professorado católico no Rio de Janeiro (2018), relata o envolvimento de Backheuser com o campo da educação primária, logo após sua aposentadoria, em 1927, da cadeira de Mineralogia e Geologia da Escola Politécnica do Rio de Janeiro. Nessa época, a convite de Fernando de Azevedo, o educador assumiu tarefas em comissões e ações específicas da Diretoria, com destaque para a participação no ciclo de conferências, em 1928, denominado A Escola Nova e a Reforma do Ensino, ao lado de Jonatas Serrano e Lourenço Filho (GONÇALVES, 2018, p. 4).

Sobre os cursos de aperfeiçoamento de professores, consagrados como espaço de autoridade profissional durante a gestão de Fernando de Azevedo, são destaque as doze conferências promovidas pela Diretoria Geral da Instrução Pública entre abril e junho de 1928, para tratar da recente reforma aprovada. Entre elas, vale mencionar as duas proferidas por Everardo Backheuser acerca da escola ativa (PAULILO, 2007).

Em relação às conferências proferidas por Backheuser, o jornal $O$ Globo, de 8 de maio de 1930, noticiou o mostrado na Fig. 1. 


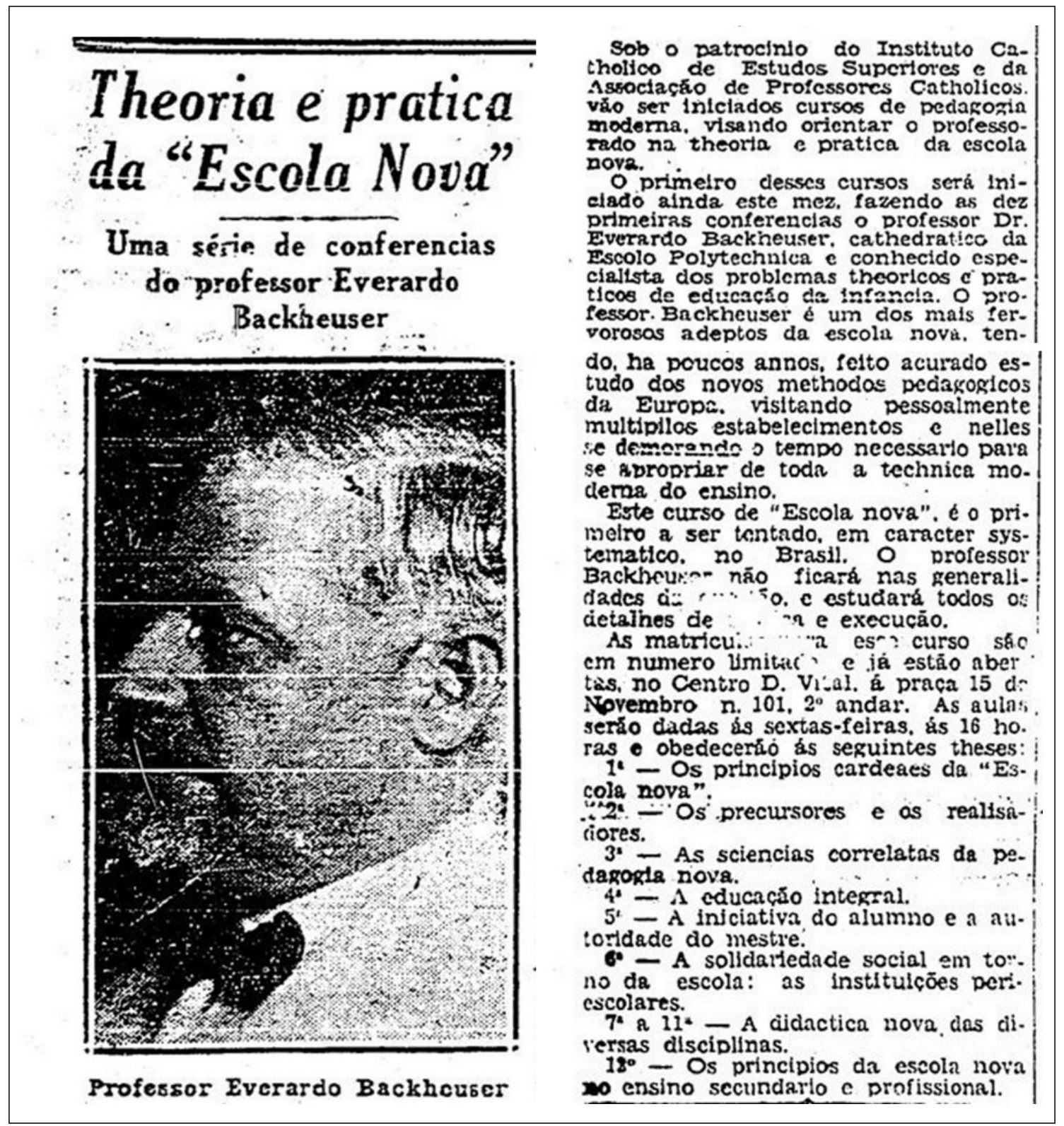

Fonte: O Globo (1930b)

Figura 1. Notícia do jornal O Globo sobre as conferências de Backheuser.

Sobre sua participação na comissão que elaborou os Programas dos Jardins de Infância e Ensino Primário durante o período em que Fernando de Azevedo esteve à frente da Diretoria Geral da Instrução Pública do Rio de Janeiro, Backheuser, no capítulo "Linhas gerais das didáticas das disciplinas", de seu livro Aritmética na Escola Nova, menciona o seguinte:

Procurando sempre fazer com que o ensino da aritmética e da geometria, como aliás das demais disciplinas, decorra da vida prática e a ela se prenda, o professor o encaminhará de modo que produza nos alunos justo equilíbrio entre o raciocínio e o cálculo mental ou escrito, ligando-os, objetivamente, a fenômenos de representação concreta, partindo do exemplo para o preceito, do fato para a exposição de princípios, dos problemas da vida quotidiana para as noções abstratas (BACKHEUSER, 1933, p. 106). 
Essa citação de Backheuser é acompanhada por uma nota de rodapé sobre os integrantes da comissão responsável pela elaboração dos programas: "Faziam parte dessa Comissão: Paulo Maranhão, Professora Maria Reis Campos, Celina Padilha, Affonsina Chagas Leite, Alcina Moreira de Souza e o autor deste livro" (BACKHEUSER, 1933, p. 106).

Na tese de Paulilo (2007), confirma-se a existência dessa comissão quando se fala do trabalho da subdiretoria técnica na gestão da Diretoria Geral da Instrução Pública do Rio de Janeiro, por Fernando de Azevedo:

As muitas comissões que cuidavam desses aspectos da implementação da reforma da instrução pública reuniam nomes reconhecidos no magistério municipal. Os Programas para os Jardins da Infância e para as Escolas Primárias detiveram a atenção de Paulo Maranhão, Everardo Backheuser, Cecilia Padilha, Maria dos Reis Campos, Affonsina das Chagas Rosa e Alcina Moreira de Souza por três meses (PAULILO, 2007, p. 70).

Foi nessa época que Backheuser iniciou a "Cruzada Pedagógica em Prol da Escola Nova”, um empreendimento que visava difundir aos professores ideias de sua concepção de Escola Nova, segundo princípios da Igreja. A iniciativa era liderada por ele e sua esposa, a professora Alcina Moreira de Souza, que, juntamente com outros representantes do magistério, organizaram conferências, cursos e exposições pedagógicas.

Como Diretor do Museu Pedagógico do Rio de Janeiro (ver Fig .2) e da Cruzada da Escola Nova, na administração de Fernando de Azevedo, Backheuser comenta:

No Museu Pedagógico e nas reuniões da Cruzada pela Escola Nova ensejaram-se-nos ocasiões múltiplas, não só de conhecer as necessidades de caráter pedagógico do magistério, como de recoltar muitas e úteis advertências que a prática lhe dava. Os resultados dessa nossa atuação foram profícuos. Muito do que se passou a fazer e a praticar em escolas do Distrito Federal teve essas despretensiosas origens. Embora nem sempre os que perfilharam as ideias tivessem ocasião de aludir às fontes de informação, muitas vezes as esquecendo, não é menos verdade que nelas se supriram para a maioria ou, pelo menos, para alguns aspectos de seus empreendimentos (BACKHEUSER, 1958, p. 20).

A respeito da instalação do Museu Pedagógico, Paulilo menciona: "A instalação do Museu Pedagógico Central teve domo responsável um engenheiro civil da Diretoria Geral de Obras particularmente ligado aos trabalhos do departamento de instrução, Everardo Backheuser” (2007, p. 138).

O estudo de Pinto (2016) estabelece comparação entre a proposta de aritmética apresentada no manual pedagógico Práticas Escolares, de autoria de Antonio D’Ávila, e a contida na obra Como se Ensina Aritmética, ${ }^{13}$ de autoria de Everardo Backheuser, observando que o engenheiro, geógrafo e pedagogo destacou-se como um dos representantes católicos estudiosos da Escola Nova, especialmente no que se refere à aritmética da escola primária em tempos de escolanovismo. Comparando as duas propostas, o estudo encontrou pontos em comum entre elas, como a preferência dada ao educador belga Ovide Decroly sua proposta de "centro de interesse", além da importância de a aritmética não perder de vista os elos com a vida real e com os interesses das crianças. Contudo, um destaque especial dado por Backheuser e que o distancia de D’Ávila é a indicação direta de um passo a passo: D’Ávila, por sua vez, deixa mais indagações do que respostas sobre que caminhos a tomar para ensinar matemática às crianças. 


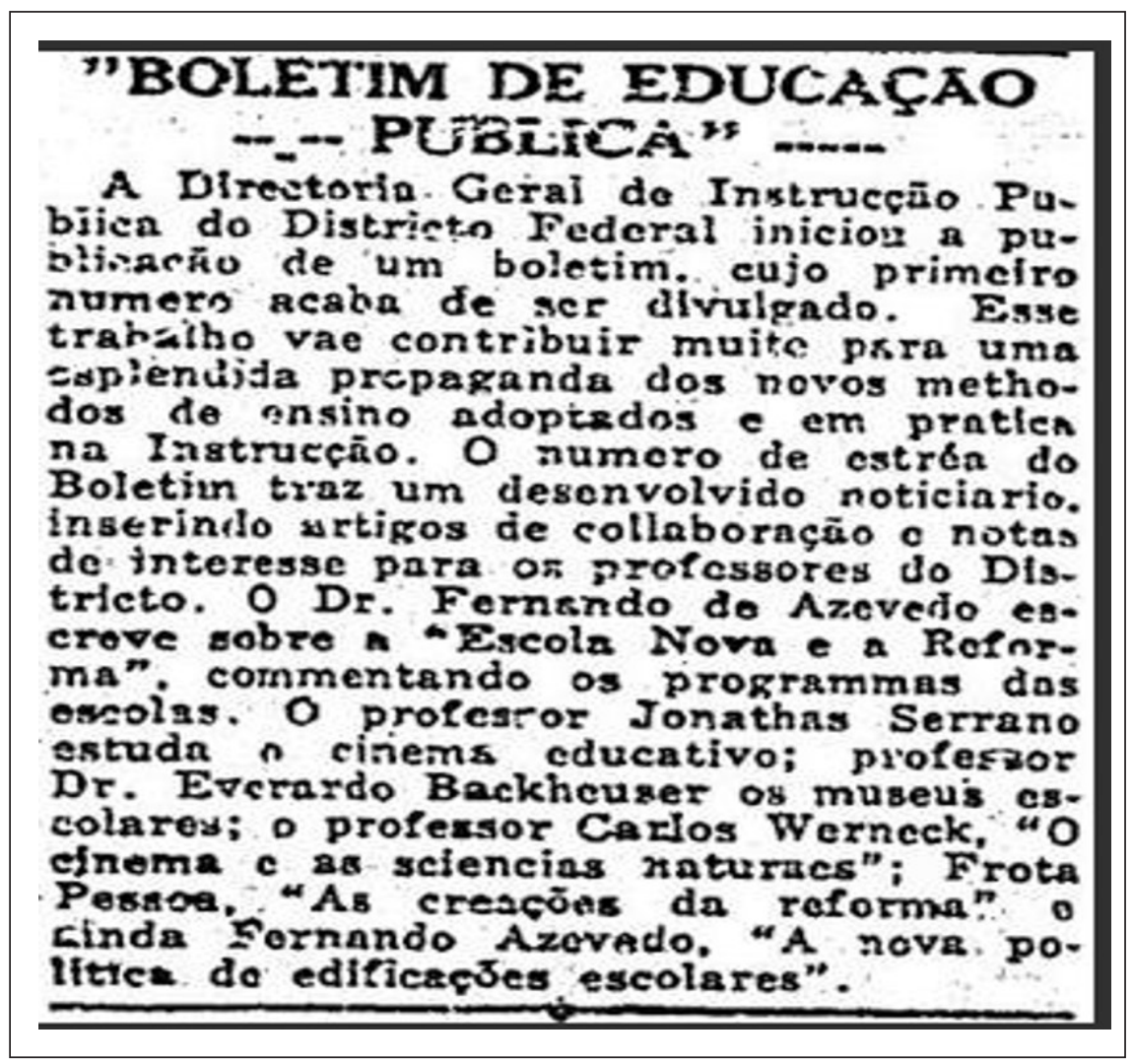

Fonte: O Globo (1930a, p. 4).

Figura 2. Notícia do jornal O Globo sobre o "Boletim da Educação Pública".

Na obra Como se Ensina Aritmética, Backheuser dialoga com ideias e preceitos de renomados pensadores da Escola Nova. Concordando com Decroly, Ferrière, Bovet e Kerschesteiner, mas discordando de Dewey, tece acirradas críticas à forma como a aritmética era ensinada, notadamente no que se refere às influências francesa e americana. Da primeira, critica o feitio decorador, essencialmente centrado na memória, na recitação de tabuadas, em contas extensas, carroções e com meia dúzia de problemas-tipo. Sobre a segunda, Backheuser critica a marcha do cálculo, ao que denominou "teorismo flou", segundo ele, "um processo mais nocivo que o anterior" (BACKHEUSER, 1946, p. 70, grifos do autor).

Para Backheuser, o estilo "mecanicista" deixava no aluno "uma petulante impressão de alto saber" e o estilo decorador, "muita modéstia e muita timidez em assuntos de matemática”. Criticava também o método de ensino das reformas dos primórdios da república, que, por influência do positivismo, partiam do simples ao composto, "quando a psicologia nos ensina que se deve com a criança caminhar exatamente no sentido inverso, isto é, do 'complexo para o elementar"' (BACKHEUSER, 1946, p. 74).

Ainda comentando o ensino da aritmética anterior à década de 1930, o autor elogia a proposta de Carneiro Leão para as escolas primárias do Distrito Federal. Leão defendeu, em 1926, um ensino prático, relacionado "aos fatos e às necessidades correntes". Backheuser também teceu elogios à proposta de Euclides Roxo, que apesar do vínculo americano, considerou como "das mais notáveis, e fortes, e benfazejas, e de tanto maior repercussão quanto, sendo ele catedrático do Colégio Pedro II, força a orientação do ensino em todos os cursos secundários" (BACKHEUSER, 1946, p. 75-76).

Outra crítica incisiva foi feita em relação à dimensão utilitarista assumida pela aritmética. Segundo ele, era um aspecto perigoso tratar o "prático", como vinha sendo valorizado na escola primária, 
o que requeria um maior conhecimento do método experimental e das influências do pragmatismo do filósofo John Dewey no ensino primário brasileiro. Aludindo a esse momento, em que as vertentes de modernização travavam disputas acirradas no cenário educacional brasileiro, Valente (2011) afirma que Lourenço Filho, apesar de defensor do escolanovismo, não conseguia avançar e sair do discurso das Cartas de Parker.

A crítica a esse material ${ }^{14}$ foi feita por Backheuser ao afirmar que "[o] aritômetro e as tabelas de Parker não só não são necessárias, como vantajosamente dispensáveis” (1933, p. 138). Para o educador, o ensino da aritmética não pode desconsiderar o lado intuitivo, a memorização, o raciocínio e o sentido prático da vida. A defesa que o autor faz dos tipos psicológicos mostra preocupações com as diferenças individuais, propondo atividades organizadas com variedade de materiais e exercícios diferenciados, que pudessem ir ao encontro dos interesses tanto dos mais teóricos e dos mais visuais como dos mais auditivos.

O estudo de Torrez e Costa (2016) comenta a classificação apresentada por Backheuser para os tipos psicológicos que balizarão uma matemática para o ensino e outra para a formação de professores.

Que relações Backheuser estabeleceu entre a matemática a ensinar e a matemática para ensinar para transformar velhos saberes em novos saberes?

\section{A Expertise de Backheuser no Campo da Educação Matemática}

Para caracterizar e delinear o perfil de um expert, contamos com aportes da abordagem sóciohistórica utilizados pelos pesquisadores que estudam a profissão docente, valendo-se de duas categorias de análise: os saberes a ensinar e os saberes para ensinar, dois importantes conceitos envolvidos na constituição dos saberes profissionais (HOFSTETTER; SCHNEUWLY; FREYMOND, 2017).

Ao relacionar o objeto de ensino (matemática a ensinar) com a ferramenta adequada para mobilizar esse saber de referência de acordo com as necessidades e os interesses das crianças (matemática para ensinar), Backheuser descreve o "passo a passo" de um processo de objetivação ${ }^{15}$ que transforma conhecimentos dispersos em saberes profissionais, indispensáveis ao exercício da docência nos primeiros anos escolares. Com isso, busca sistematizar uma aritmética escolanovista, sem perder de vista três princípios básicos: raciocínio, memória, o preparo para a vida - priorizados após dialogar com diferentes vertentes da Escola Nova. Em torno dos maus usos desses conceitos, o autor teceu suas críticas no intento de sistematizar uma nova aritmética para a escola primária, coerente com os propósitos da reforma proposta por Fernando de Azevedo em 1928.

Esse processo fica bem visível nas páginas finais de Aritmética na Escola Nova, quando são propostos usos considerados "apropriados" para ensinar aritmética na escola primária segundo a concepção escolanovista de Backheuser - uma proposta decorrente, certamente, do diálogo que esse estudioso estabeleceu com diferentes campos disciplinares, como matemática, psicologia da educação, sociologia da educação e didática, disciplinas integrantes dos cursos de formação de normalistas, portadoras de conhecimentos necessários à construção de uma profissionalidade docente.

Nesse diálogo, o autor em questão descarta os maus usos da tabuada, da memória e do conceito de concreto, delineando uma nova configuração programática para ensinar uma aritmética prática, não utilitarista, pertinente a uma escola ativa. "Nem nós nem ninguém louva os exercícios secos de tabuada, porque inibem a memória em vez de desenvolvê-la, mas também não basta fazer cálculos mentais sem habituar, enfim, a criança a realizá-la com facilidade e depressa” (BACKHEUSER, 1933, p. 94). 
Para o educador, cada fase da criança deve ser respeitada e a aritmética trabalhada com atividades específicas e materiais adequados.

\begin{abstract}
As atividades sugeridas são organizadas a partir dos pressupostos teóricos defendidos no livro, como o caráter prático, entendido como utilidade na vida do aluno. Nesse sentido, são sugeridas atividades com jogos, compra de objetos escolares, vida doméstica, enfim, atividades que o autor considera como sendo do interesse da criança, não do adulto, e que ainda sejam, tanto quanto possível, adequadas às diferenças. [...] Recomenda que nos dois primeiros anos (fase de sintese fantasista), as atividades sejam graduadas, o ensino da Aritmética tenha um caráter concreto (intuitivo) e envolva as demais matérias com aulas ministradas apenas por uma professora. Nas últimas séries, fase de análise crítica, propõe que sejam incluídas atividades com discussão, desenvolvimento de memória e raciocínio (PINTO, 2016, p.182).
\end{abstract}

Ao cálculo mental foi dada uma atenção especial, com a organização de um passo a passo que levasse em conta a importância dessa habilidade para o desenvolvimento da memória, do raciocínio e da rapidez necessária a cálculo. Observa Backheuser que, tanto nos programas de 1926, elaborados na gestão de Carneiro Leão, quanto nos de 1928, na gestão de Fernando de Azevedo, são recomendados, para todas as classes, exercícios de cálculo mental, seja para acordar a mente infantil para que efetue as operações aritméticas, seja pela sua utilidade na vida, ao preparar a mente para o manejo rápido do cálculo (BACKHEUSER, 1933, p. 100).

Seguindo recomendação de Binet (1910 apud BACKHEUSER, 1933, p. 144), em excerto extraído da obra Les Idées Modernes sur les Enfants, Backheuser também considera que é na infância, aproveitando-se a plasticidade da criança, que a memória deve ser cultivada para guardar recordações decisivas para a vida adulta.

Em relação ao cálculo mental, o autor adverte que "os visuais precisam de ver a conta escrita; os auditivos, de ouvirem os números enunciados; os motores, de escreverem eles mesmos os algarismos". Referindo-se ao uso do lápis na preparação das atividades, lembra que o trabalho escrito é mais lento "quando a operação entre números não está fresca na memória" (BACKHEUSER, 1933, p. 144). Ainda sobre um bom uso do cálculo mental na aritmética, recomenda que:
a. O treino do cálculo mental deve ser feito em grupo;
b. Tenha por objetivo garantir segurança e rapidez nas operações;
c. Tenha exercícios concretos, pequenos problemas que não necessitam de lápis e papel;
d. Tenha exercícios fáceis de resolver;
e. Tenha assuntos que interessem à classe (BACKHEUSER, 1933, p. 144).

Denominando "artifícios de cálculo mental", o engenheiro, pedagogo e matemático realizou uma expertise no campo da educação matemática, ao sistematizar um processo e apontar "novos saberes": saberes profissionais para o ensino do cálculo mental na escola primária. É o que indicam as "marchas do cálculo mental" para diferentes operações aritméticas, apresentadas nas últimas páginas (141 a 152) da obra Aritmética na Escola Nova, espaço no qual o autor estabeleceu relação entre uma aritmética a ensinar e uma aritmética para ensinar cálculo mental na escola primária (Fig. 3). 


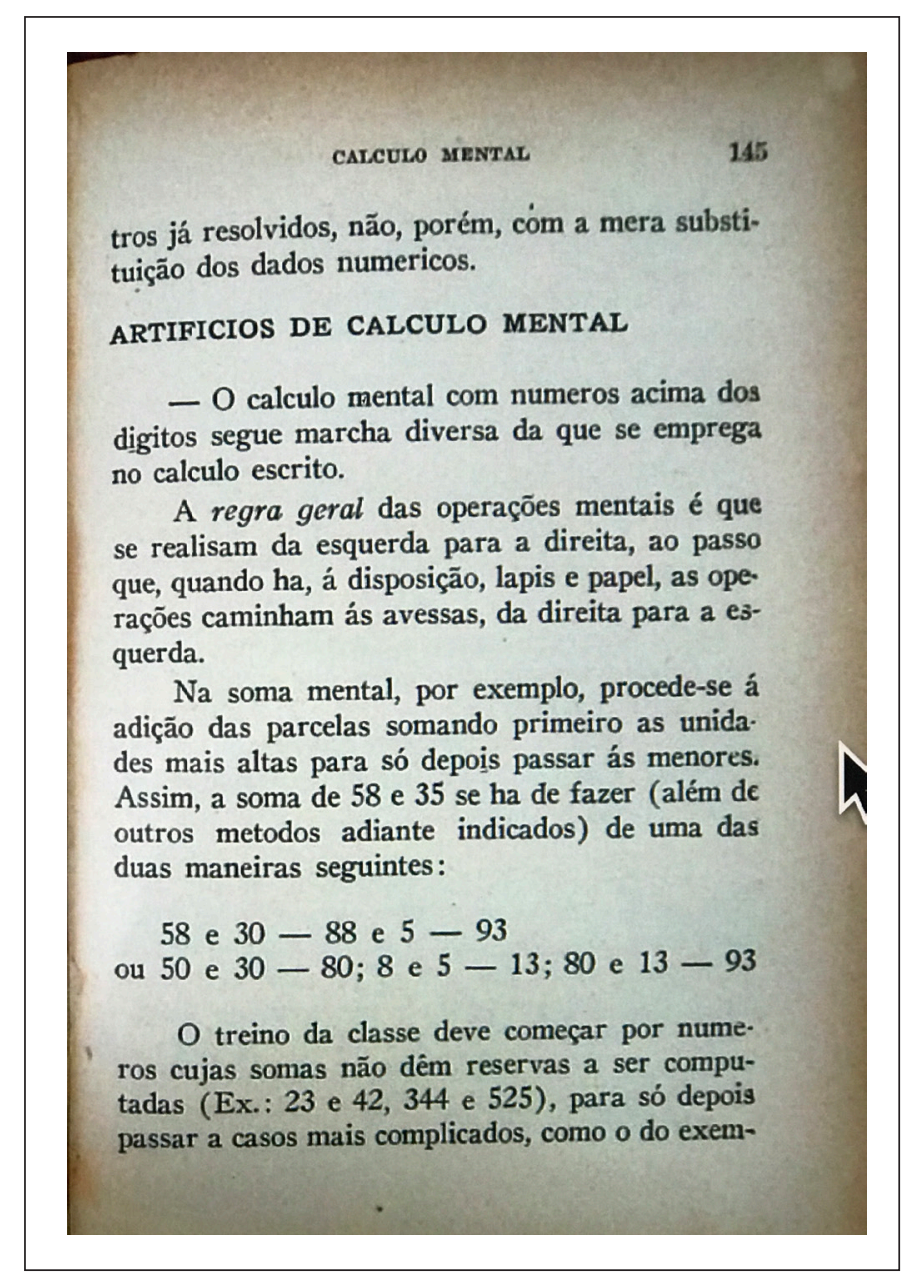

Fonte: Backheuser (1933, p. 145).

Figura 3. Página de um dos livros de Backheuser.

\section{Considerações Finais}

A reforma realizada por Fernando de Azevedo em 1928 no Rio de Janeiro, como ele próprio afirmou, não foi apenas uma reforma de métodos pedagógicos. Teve como horizonte uma nova finalidade pedagógica e social, ao reconhecer os novos desafios colocados pelo crescimento da indústria e que a escola, principalmente a escola primária, precisaria responder propiciando a todos a aquisição de um saber básico, necessário para a entrada do indivíduo no mundo do trabalho.

Ao saudar Fernando de Azevedo, por ocasião da inauguração da "Exposição Pedagógica”, Backheuser enfatiza, em seu discurso, a real finalidade da reforma:

Nela [reforma], não se trata de substituir um método por outro método, o processo de silabação pelo processo de sentenciação; o ensino dedutivo pelo ensino indutivo; os programas sistemáticos pelo estudo de conjunto ou pelos centros de interesses; Herbart por Froebel; Montessori por Decroly. Não. Se fosse isto, apesar de parecer muito, seria afinal pouco, porque não revela transcendente descortino nem apresenta insuperável dificuldade de calcar com jeito uma metodologia, revestindo ou não este modesto trabalho com títulos mais ou menos pomposos de adaptação e brasilianização. Se fosse só isso, seria, como já o dissestes, em aforismo lapidar, "substituir uma rotina por outra rotina”. A Reforma é muito mais que uma metamorfose 
de fórmulas metodológicas [...] é, antes de tudo, uma reforma de ordem social. Foi a socialização da escola o que procurastes focalizar (BACKHEUSER, 1929 apud PENNA, 2010, p. 54).

Com esse argumento, Backheuser projetou uma nova aritmética para enfrentar os desafios dos novos tempos.

O percurso profissional do educador em questão, perpassado por ações e iniciativas voltadas a uma educação fundamentada em novos preceitos e ideias escolanovistas, permite afirmar que construiu uma expertise no período em que colaborou com a elaboração e a implementação da reforma do ensino proposta por Fernando de Azevedo, no período entre 1927 a 1930. O conhecimento que buscou acerca da Escola Nova, inclusive visitando países europeus; o diálogo que estabeleceu com propostas de uma escola sob medida, de um ensino ativo; o conhecimento novo, que resultou de um processo de comparação com outras formas de ensinar aritmética na escola primária atenderam a condições enunciadas na base teórica em relação ao conceito de expert; ou seja, Everardo Adolpho Backheuser realizou uma expertise profissional, ao atender uma convocatória de Fernando de Azevedo, Diretor Geral da Instrução Pública do Rio de Janeiro no período de 1927 a 1930. Para além de integrar a comissão responsável por essa tarefa, Backheuser atuou na divulgação da nova proposta educativa entre professores em serviço, seja pelas atividades da Cruzada em Prol da Escola Nova e do Museu Pedagógico, entidades que dirigiu, seja com a realização de conferências sobre temas da nova reforma de ensino. Outro requisito atendido foi trazer, em sua obra Aritmética na Escola Nova, os fundamentos e argumentos sobre mudanças na proposta para ensinar essa disciplina segundo o escolanovismo, elementos que caracterizam o perfil de um expert, qualificando Everardo Adolpho Backheuser como um expert da educação matemática.

\section{Notas}

1. Na década de 1920, foram realizadas as seguintes reformas: em São Paulo (1920), por Sampaio Dória; no Rio de Janeiro, então Distrito Federal (1922-1926), por Carneiro Leão; no Ceará (1923-1928), por Lourenço Filho; na Bahia (1927), por Anísio Teixeira; em Minas Gerais (1928), por Francisco Campos; no Rio de Janeiro, então Distrito Federal (1928), por Fernando de Azevedo (NAGLE, 2009).

2. Entre outras publicações do autor em análise voltadas à formação dos professores do ensino primário em tempos escolanovistas, a obra mencionada é apontada por Silva (2003) como uma das mais citadas entre os anos de 1947 e 1959. Nela, sob os pressupostos da Escola Nova, o autor explicita saberes considerados fundamentais para o ensino da matemática nos primeiros anos escolares.

3. VALENTE, 2017-2022; 2018-2020.

4. Equipe de pesquisa da história das ciências da educação da Universidade de Genebra, sob coordenação da professora Rita Hofstetter.

5. A expressão saberes a ensinar refere-se ao objeto de ensino. Já a expressão saberes para ensinar refere-se às ferramentas utilizadas para ensinar os saberes.

6. Dossiê "Experts e a sistematização dos saberes matemáticos para o ensino e para a formação de professores" (REMATEC - Revista de Matemática, Ensino e Cultura, ano 15, n. 34, maio/ago. 2020).

7. Termo cunhado por Carvalho (2003). 
8. Conceitos centrais na discussão dos saberes profissionais que, de acordo com Hofstetter, Schneuwly e Freymond (2017), referem-se, respectivamente, ao objeto de trabalho (saberes a ensinar) e às ferramentas de trabalho do professor, ou seja, saberes sobre o ensino de seu objeto de trabalho (saberes para ensinar).

9. Expertise aqui empregada no sentido utilizado por Morais, "de reconhecimento da competência daquele que detém os saberes necessários para realizar tarefas que lhes são designadas, o expert” (2017, p. 62).

10. Sobre circulação de manuais pedagógicos, ver Silva (2003).

11. Tese orientada pela Profa. Dra. Gladys Mary Ghizoni Teive, defendida em 10 de abril de 2017, no Programa em Educação Universidade do Estado de Santa Catarina (UDESC), área de História da Educação.

12. Termo que a autora utilizou para referir-se à representação de Everardo Backheuser sobre a Escola Nova.

13. Backheuser publicou, em 1933, pela Livraria Católica, a obra Aritmética na Escola Nova e, em 1946, pela Editora Livraria Globo, a obra Como se ensina Aritmética. Apesar de títulos e editoras diferentes, ambas tratam do mesmo tema e apresentam o mesmo sumário.

14. “As Cartas de Parker, material didático-pedagógico oriundo dos Estados Unidos e elaborado por Francis Wayland Parker, foram amplamente disseminados e utilizados nos grupos escolares de vários estados do Brasil. No Paraná, esse material foi intensamente difundido por Prieto Martinez e, até meados dos anos de 1950, marcou presença em salas de aula da escola primária do estado" (PINTO, 2016). Sobre esse material, ver Valente (2011) e Portela (2014).

15. Ver discussão sobre o conceito de saber objetivado em Valente (2019).

\section{REFERÊNCIAS}

BACKHEUSER, E. A. A aritmética na “Escola Nova”. A nova didática da Aritmética. Rio de Janeiro: Livraria Católica, 1933. Disponível em: https://repositorio.ufsc.br/xmlui/handle/123456789/134889. Acesso em: 23 jun. 2020.

BACKHEUSER, E. A. Como se ensina a Aritmética. Fundamentos Psicopedagógicos. Rio de Janeiro/Porto Alegre/São Paulo: Edição da Livraria da Globo, 1946. (Coleção Vida e Educação, v. 9.)

BACKHEUSER, E. A. Manual de Pedagogia Moderna: teoria e prática. Porto Alegre: Editora Globo, 1958.

BERTINI, L. F.; MORAIS, R. S.; VALENTE, W. R. A matemática a ensinar e a matemática para ensinar novos estudos sobre a formação de professores. São Paulo: L. F. Editora, 2017.

BURKE, P. O que é história do conhecimento? São Paulo: Editora Unesp, 2016.

CARVALHO, M. M. C. A escola e a república e outros ensaios. Bragança Paulista: EDUSF, 2003.

CHOPPIN, A. Pasado y presente de los manuales escolares. In: BERRIO, J. D. (org.). La cultura escolar de Europa. Tendências históricas emergentes. Madrid: Editorial Biblioteca Nueva, 2000. p. 107-167. 
D’ESQUIVEL, M. O. Primeiras noções de geometria prática (1894-1966): a obra e as mudanças no saber profissional do professor que ensina geometria. 2019. 143 f. Tese (Doutorado em Ciências) - Escola de Filosofia, Letras e Ciências Humanas, Programa de Pós-graduação em Educação e Saúde na Infância e na Adolescência, Universidade Federal de São Paulo, Guarulhos, 2019.

GONÇALVES, M. C. A cruzada pedagógica pela Escola Nova e ação do professorado católico no rio de Janeiro (final da década de 1920). Revista Educação Unisinos, São Leopoldo, v. 22, n. 3, p. 1-16, 2018. https://doi. org/10.4013/edu.2018.223.06

HOFSTETTER, R. Apresentação. In: HOFSTETTER, R.; VALENTE, W. R. (orgs.). Saberes em (trans) formação: tema central da formação de professores. São Paulo: Editora Livraria da Física, 2017. p. 115-19. (Coleção Contexto da Ciência.)

HOFSTETTER, R.; SCHNEUWLY, B.; FREYMOND, M. Penetrar na verdade da escola para ter elementos concretos de sua avaliação: a irresistível institucionalização do expert em educação (século XIX e XX). In: HOFSTETTER, R.; VALENTE, W. R. (orgs.). Saberes em (trans)formação: tema central a formação de professores. São Paulo: Editora Livraria da Física, 2017. p. 55-112.

HOFSTETTER, R.; VALENTE, W. R. (orgs.). Saberes em (trans)formação: tema central da formação de professores. São Paulo: Editora Livraria da Física, 2017. (Coleção Contexto da Ciência.)

JULIA, D. A cultura escolar como objeto histórico. Revista Brasileira de História da Educação, Campinas, n. 1, p. 9-43, jan./abr. 2001.

MACIEL, V. B. Elementos do saber profissional do professor que ensina matemática: uma matemática para ensinar nos manuais pedagógicos. 2017. Tese (Doutorado em Ciências) - Escola de Filosofia, Letras e Ciências Humanas, Programa de Pós-graduação em Educação e Saúde na Infância e na Adolescência, Universidade Federal de São Paulo, Guarulhos, 2019.

MORAIS, R. S. Experts em educação e a produção de saberes no campo pedagógico. REMATEC - Revista de Matemática, Ensino e Cultura, Belém, ano 12, n. 26, p. 61-70, set./dez. 2017. https://doi.org/10.37084/ REMATEC.1980-3141.2017.n26.p\%p.id110

MORAIS, R. S. “Intelectual? Não”, expert. Acta Scientiae, Canoas, v. 21, n. esp., p. 3-12, maio/jun. 2019.

MORAIS, R. S. Expert em educação matemática. 2020. Trabalho apresentado on-line ao XVIII Seminário Temático os Experts e a Sistematização da Matemática para o Ensino e Formação de Professores, [s. 1.], 20 jun. 2020.

NAGLE, J. Educação e sociedade na Primeira República. 3. ed. São Paulo: EDUSP, 2009.

O GLOBO. Geral, 10 fev. 1930a, p. 4.

O GLOBO. 8 maio 1930b. 
PAULILO, A. L. A estratégia como invenção: as políticas públicas de educação na cidade do Rio de Janeiro entre 1922 e 1935. 2007. Tese (Doutorado em Educação) - Programa de Pós-graduação em Educação, Faculdade de Educação, Universidade de São Paulo, São Paulo, 2007.

PENNA, M. L. Fernando de Azevedo. Recife: Fundação Joaquim Nabuco/Editora Massangana, 2010. 162 p.

PINHEIRO, N. V. L. A Aritmética sob medida: a matemática em tempos da pedagogia científica. 2017.224f. Tese (Doutorado em Ciências) - Escola de Filosofia, Letras e Ciências Humanas, Programa de Pós-graduação em Educação e Saúde na Infância e na Adolescência, Universidade Federal de São Paulo, Guarulhos, 2017.

PINTO, N. B. Matrizes pedagógicas de manuais que ensinam a ensinar aritmética na escola primária em tempos de Escola Nova: aproximações e distanciamentos. HISTEMAT - Revista de História da Educação Matemática, [s. 1.], ano 2, n.1, p. 173-189, 2016.

PORTELA, M. S. As cartas de Parker na Matemática da escola primária paranaense na primeira metade do século XX: circulação e apropriação de um dispositivo didático. 2014. 191 f. Tese (Doutorado em Educação) - Escola de Educação e Humanidades, Pontifícia Universidade Católica do Paraná, Curitiba, 2014. Disponível em: https://repositorio.ufsc.br/handle/123456789/128465. Acesso em: 16 jan. 2020.

ROSA, M. Escolanovismo Católico Backheusiano: apropriações e representações da Escola Nova tecidas em manuais pedagógicos (1930-1940). 2017. Tese (Doutorado em Educação) - Centro de Ciências Humanas e da Educação, Programa de Pós-Graduação em Educação, Universidade do Estado de Santa Catarina, Florianópolis, 2017.

SANTOS, S. M. G. A cultura opulenta de Everaldo Backheuser: conceitos e leis básicas da geopolítica. Rio de Janeiro: Ed. Carioca de Engenharia, 1989.

SCHNEUWLY, B. A irresistível institucionalização dos experts em educação. 2020. Trabalho apresentado on-line ao XVIII Seminário Temático os Experts e a Sistematização da Matemática para o Ensino e Formação de Professores, [s. 1.], 6 jun. 2020.

SILVA, M. R. I. S. A matemática para a formação do professor do curso primário: aritmética como um saber profissional, 1920-1960. Tese (Doutorado em Ciências) - Escola de Filosofia, Letras e Ciências Humanas, Programa de Pós-graduação em Educação e Saúde na Infância e na Adolescência, Universidade Federal de São Paulo, Guarulhos, 2017.

SILVA, V. B. Uma história das leituras para professores: análise da produção e circulação de saberes especializados nos manuais pedagógicos (1930-1971). Revista Brasileira de História da Educação, Campinas, v. 6, p. 29-58, 2003. Disponível em: http://periodicos.uem.br/ojs/index.php/rbhe/article/view/38695. Acesso em: maio 2019.

TORREZ, C. T. B.; COSTA, D. A. A psicologia no manual de aritmética de Backheuser. Caminhos da Educação Matemática em Revista, Aracaju, v. 5, n. 1, p. 68-79, 2016.

VALENTE, W. R. A matemática na formação do professor do ensino primário. São Paulo: Annablume/ Fapesp, 2011. 
VALENTE, W. R. Os movimentos da matemática na escola: do ensino de matemática para a educação matemática; da educação matemática para o ensino de matemática; do ensino de matemática para a Educação Matemática; da Educação Matemática para o Ensino de Matemática? Pensar a Educação em Revista, Curitiba/Belo Horizonte, v. 2, n. 2, p. 3-23, abr./jun. 2016.

VALENTE, W. R. (coord.). A Matemática na formação de professores e no ensino: processos e dinâmicas de produção de um saber profissional, 1890-1990. São Paulo: Fapesp, 2017-2022.

VALENTE, W. R. (coord.). Os experts e a sistematização da Matemática para a formação de professores dos primeiros anos escolares, 1890-1990. Distrito Federal: MCTIC/CNPq, 2018-2020.

VALENTE, W. R. Saber objetivado e formação de professores: reflexões pedagógico-epistemológicas. Revista História da Educação, São Leopoldo, v. 23, e77747, p. 1-22, 2019.

VALENTE, W. R. Editorial. Experts e a sistematização dos saberes matemáticos para o ensino e para a formação de professores. REMATEC - Revista de Matemática, Ensino e Cultura, Belém, ano 15, n. 34, maio/ ago., p. 6-7, 2020a.

VALENTE, W. R. Expert em educação matemática. 2020. Trabalho apresentado on-line ao XVIII Seminário Temático os Experts e a Sistematização da Matemática para o Ensino e Formação de Professores, [s. 1.], 20 jun. 2020b.

Recebido: 16 Nov. 2020

Aceito: 06 Maio 2021

Editoras Associadas:

Alessandra Arce Hai e Ana Clara Bortoleto Nery 